\title{
PNEUMOTHORACES IN LATE PRE-TERM AND TERM INFANTS: 50 CASES IN A UK DISTRICT GENERAL HOSPITAL \\ Dr C Fraser ${ }^{1}$, Dr K Cooke ${ }^{2}$, Dr M Wickramasinghe ${ }^{2}$, Dr K Deakin ${ }^{3}$ MidYorkshire Hospitals, Wakefield, West Yorkshire, UK
}

\section{$\underline{\text { Aim }}$}

To review the risk factors for pneumothoraces, including a review of the risk factors and indications for chest drain insertion.

\section{Method}

Review of babies $>32 / 40$ gestation with a pneumothorax between June 2011 and March 2018. Used 'BadgerNet', 'ICE' (results server), 'PACS' (radiology software),

'Windip' (scanned notes software) to obtain information.

\section{Results}

Total of 50 babies, $23(46 \%)$ of whom required chest drain insertion.

All occurred within $\mathbf{7 2}$ hours of life. $\mathbf{7 4 \%}$ were in boys.

The 3 main risk factors for pneumothorax were: male sex, inflation/ventilation breaths at birth and delivery via $\mathbf{C}$ section.

The indications for chest drain insertion as per regional guidelines were met in $\mathbf{9 1 \%}$ of the babies who had chest drains sited.

Number of risk factors per baby for pneumothorax

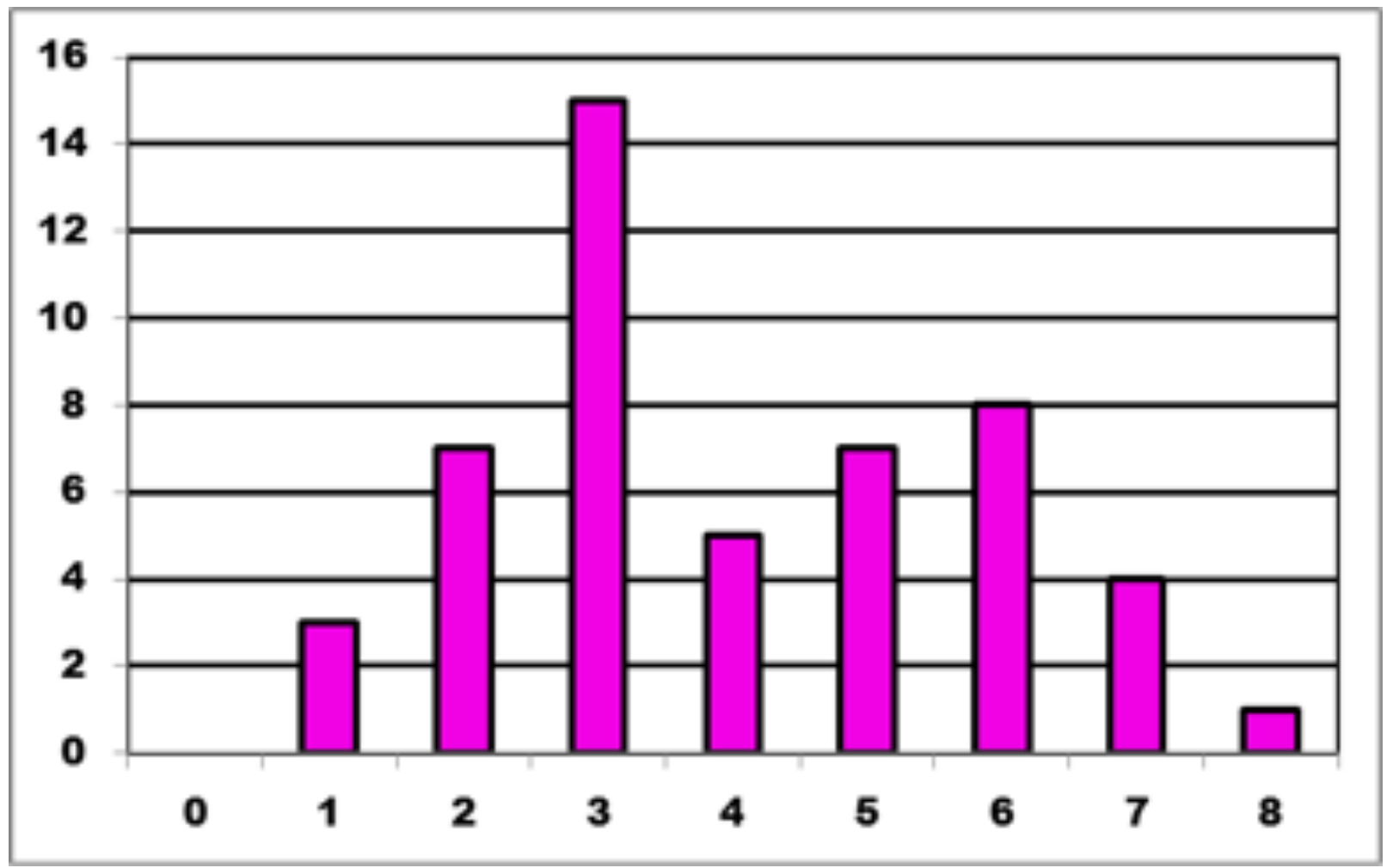

250 babies had CPAP in this time period and gestation: 14 developed a pneumothorax (5.6\%). 114 babies received high flow, 4 of whom had a pneumothorax (3.5\%).

Term infants more commonly had pneumothoraces but preterm infants more commonly required chest drains.

\section{Respiratory support and chest drain insertion}

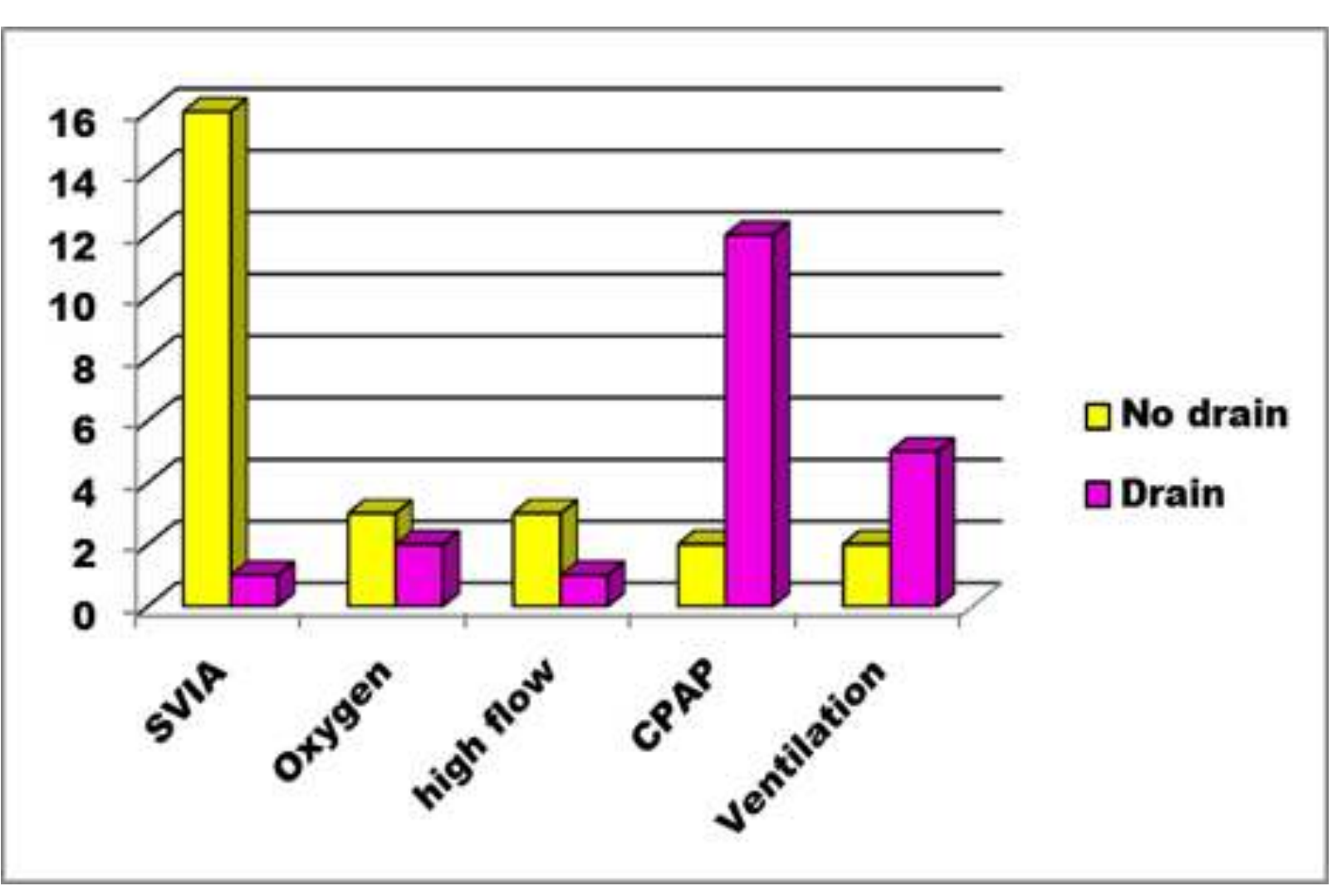

Risk Factors for pneumothorax

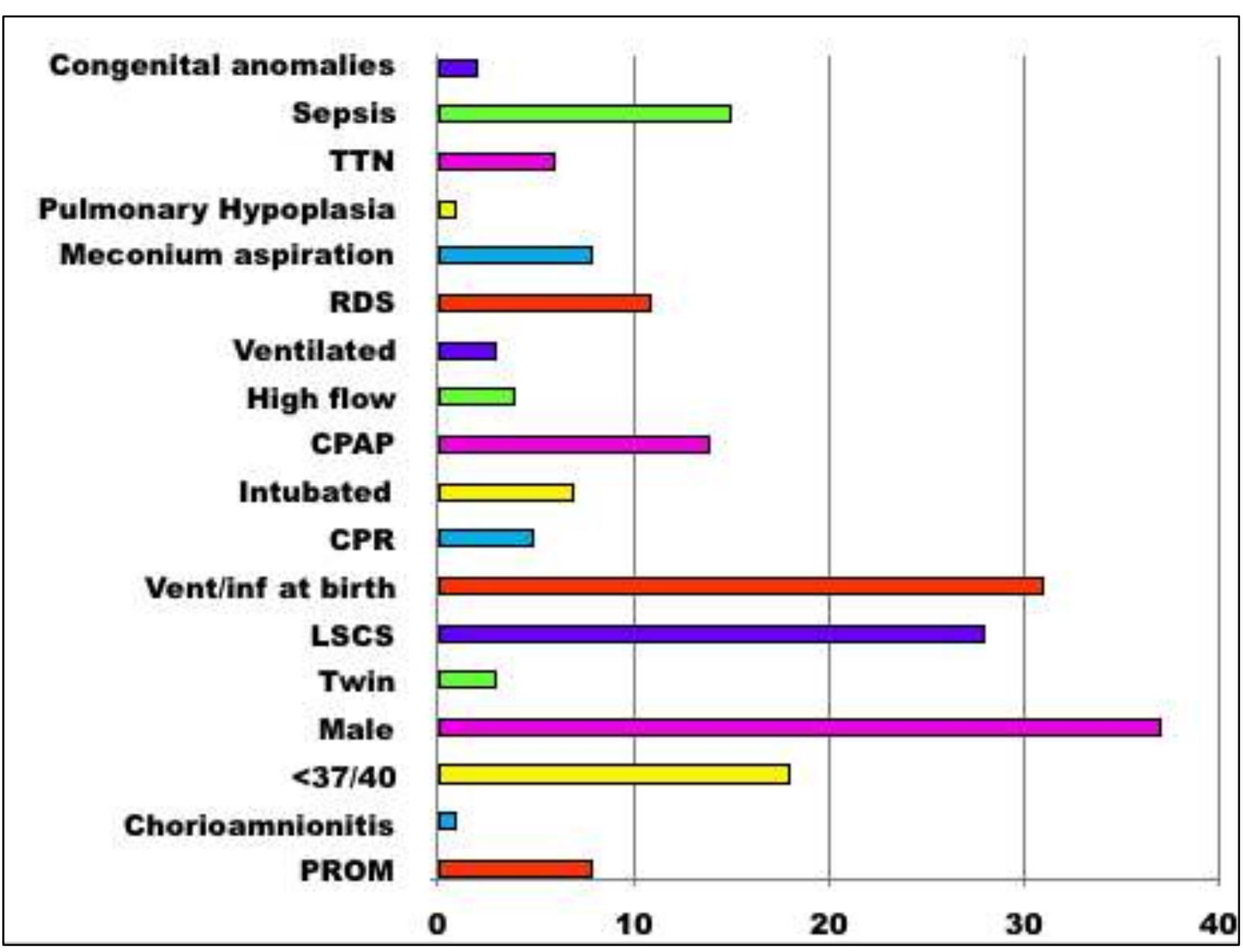

Conclusions

All babies had risk factors for pneumothoraces, most commonly 3.

CPAP was a particular risk factor for significant pneumothoraces requiring chest drain insertion.

Almost half the babies (46\%) required chest drain insertion.

Further evidence supporting therapeutic aspiration compared to drain insertion could help decrease drain rates.

\section{References}

